\title{
¿Cuáles son las medidas de prevención contra el Novel Coronavirus (COVID-19)?
}

\section{Which are the prevention measures against Novel Coronavirus (COVID-19)?}

\author{
Hilda G Hernández Orozco, ${ }^{*}$ Martha S Ramiro Mendoza, ${ }^{\ddagger}$ Roxana Trejo González ${ }^{\S}$ \\ * Comité de Infecciones Asociadas a la Atención de la Salud, Instituto Nacional de Pediatría. \\ ₹ Servicio de Epidemiología, Instituto Nacional de Pediatría. \\ $\S$ Gerente de Epidemiología y Control de Infecciones The American British Cowdray, Medical Center, IAP.
}

La herramienta más poderosa de prevención es la información, al igual que compartirla de manera correcta y responsable para que todos conozcan el riesgo y las medidas de seguridad a llevar a cabo; por ello, como personal de salud, estamos obligados a ser los voceros de esta información para que se difunda responsablemente por otros, por ejemplo, los medios de comunicación. Saber que las autoridades de salud de China conocen perfectamente lo que está sucediendo en el brote y su excelente sistema de vigilancia, nos hace reflexionar sobre la importancia de tener un sistema de vigilancia eficiente (no sólo para los virus sino también para otros microorganismos, incluyendo los multidrogorresistentes) para la notificación de enfermedades emergentes y brotes a nivel nacional con una adecuada retroalimentación. Es importante que las autoridades ejerzan su liderazgo al conocer perfectamente esta información y apoyen la gestión de recursos, para que los programas de prevención se realicen en cada institución de salud en forma apropiada, buscando esa cultura de seguridad de cada uno de los que trabajamos en las instituciones de salud para hacer frente a estas emergencias.

Ahora, se sabe que el primer caso de neumonía por COVID-19 ocurrió en Wuhan, China, en 2019. La revisión de 425 casos en la revista The New England Journal of Medicine mostró que los casos

Financiamiento: Ninguno.

Conflicto de intereses: Ninguno.

https://dx.doi.org/10.35366/92380

Rev Latin Infect Pediatr 2020; 33 (1): 4-6 se presentaban en pacientes con una media de edad de 59 años; $56 \%$ eran masculinos y la asociación epidemiológica era el mercado de animales vivos y mariscos. El periodo de incubación promedio es de cinco días, con un rango entre cuatro y 14 días, así como una trasmisión de humano a humano, estimando que el R0 (velocidad con que una enfermedad puede propagarse) es de 2.2 a 3.7. El contagio es a través de gotas o estrecho contacto con personas $u$ objetos contaminados con el virus. No se presentaron casos en menores de 15 años, por lo que se deduce que eran asintomáticos o con sintomatología leve; sin embargo, sí se presentaron casos en personal de salud. ${ }^{1}$

¿Por qué se detectaron estos casos? Porque existía una estrategia de vigilancia para «neumonía de origen desconocido» establecida en 2003 para el síndrome respiratorio agudo grave (SARS, por sus siglas en inglés). ¿Los criterios para ello? Pacientes con fiebre $>38$ oC, evidencia de neumonía en la radiografía sin identificar la etiología, cuenta leucocitaria baja o normal y no mejoría después de tres a cinco días de tratamiento antimicrobiano. ${ }^{2} \mathrm{Al}$ detectar el COVID-19 se agregó como definición de caso el que hubieran estado en Wuhan o China 14 días previos o que fueran contacto de un caso sospechoso o confirmado. El caso confirmado tiene una prueba positiva para COVID-19 por RT-PCR. ${ }^{3-5}$ Actualmente, la definición de caso sólo incluye pacientes que presentan enfermedad respiratoria aguda o grave, y que cuenten con antecedentes de 14 días previos de viaje a países con trasmisión local comunitaria de COVID-19: China, Corea del Sur, Japón, Italia, Irán y Singapur o estar en 
contacto con un caso confirmado o en investigación de COVID-19.

Derivado de la evaluación constante del comportamiento del brote, el 30 de enero de 2020, el Comité de Emergencias convocado por el Director General de la OMS en virtud del Reglamento Sanitario Internacional (RSI [2005]) se reunió y declaró al evento de COVID-19 como una emergencia de salud pública de importancia internacional (ESPII), y recomendó a todos los países estar preparados para adoptar medidas de contención, tales como la vigilancia activa, la detección temprana, el aislamiento y el manejo de los casos, el seguimiento de contactos y la prevención de la propagación del COVID-19. ${ }^{6}$

La medida inicial de prevención será una vigilancia epidemiológica estrecha y realizar las estrategias de acción oportuna si se presentara un caso. Por otro lado, se conocen ampliamente las medidas de prevención; primero pensemos en las dos vías de ingreso de los pacientes por urgencias o consulta, así que son los sitios para aplicar las siguientes medidas:

1. Un triage que permita reconocer los supuestos casos rápidamente. Este triage incluye la capacitación del personal y público para conocer los datos clínicos de sospecha: infección respiratoria aguda sin otra etiología, fiebre, tos y necesidad de internamiento en el hospital, con el antecedente de viaje a China o países con trasmisión interna 14 días previos, o contacto con un caso probable o confirmado de COVID-19.

2. Aplicar las precauciones estándar a todos los pacientes, recordemos la regla universal, el equipo protector se usará de acuerdo al procedimiento de atención al paciente que realicemos y la más simple e importante es la higiene de manos con solución alcoholada o con agua y jabón en los cinco momentos básicos con la frecuencia requerida, según el riesgo de exposición, especialmente después del contacto con secreciones; así como el uso de la etiqueta tos -mascarilla quirúrgica, cubrir boca y nariz al estornudar o toser con la parte interna del codo o un pañuelo, eliminar el pañuelo desechable después de su uso y, por supuesto, realizar higiene de manos-. La separación entre las camas de al menos un metro de distancia disminuye el riesgo de trasmisión. Debemos realizar todos los procedimientos con técnica aséptica, llevar a cabo la limpieza, desinfección y esterilización del material y equipo utilizado en la atención del paciente.

3. Implementar precauciones basadas en la trasmisión o específicas de aislamiento por gotas y contacto para los pacientes probablemente infectados o casos confirmados; el tiempo por ahora es hasta tener dos resultados negativos o hasta que no haya más casos, aun cuando se hayan controlado los síntomas, ya que se discute la posible trasmisión en personas asintomáticas; tal vez esto cambie de acuerdo con el avance del conocimiento del COVID-19. Además, debe colocarse cartelones para que se sigan medidas de prevención (toda persona con infección respiratoria usa mascarilla quirúrgica y realiza higiene de manos frecuente), y tratar de tener espacio para separarlas de otros pacientes. Idealmente, debemos tener cuartos individuales de aislamiento o al menos colocar a todos los sospechosos o confirmados en ambientes comunes separados de otros pacientes. Realizar estudios radiográficos con equipos portátiles o si se requiere enviar al área, se avisará a ésta para que se tomen las medidas adecuadas y después de la atención del paciente se realice la limpieza del lugar y del equipo utilizado. Como pueden ver, son las medidas que estamos llevando todos los hospitales en esta temporada de influenza, así que eso debería darnos la seguridad de que el riesgo puede ser controlado, ya que se actúa de manera adecuada en los hospitales actualmente.

En los casos de COVID-19 sería ideal tener un equipo médico y de enfermería asignado para la atención de éstos y, como siempre, se recomienda restringir el personal y visitantes para estos pacientes al mínimo necesario. Además, usar goggles o careta para evitar la contaminación de mucosas, bata de manga larga, guantes y mascarilla quirúrgica, debiendo cambiar este equipo entre paciente y paciente.

Idealmente, debemos usar un baumanómetro, estetoscopio, termómetro, etcétera para cada paciente con sospecha o caso confirmado de COVID-19; sin embargo, si es necesario usarlo con otro paciente se debe desinfectar con alcohol al $70 \%$.

Como nos enfrentamos a un nuevo virus del cual aún no se conoce un tratamiento antiviral efectivo o vacuna, se recomienda que se use mascarilla N95 cuando se realice intubación, broncoscopia, traqueostomía, resucitación cardiopulmonar del paciente e, incluso, la toma de muestras si existe el riesgo de generar aerosoles; siguiendo las normas de uso de mascarilla N95, así como realizar estos procedimientos en áreas con 12 intercambios de aire por hora.

4. Implementar las medidas administrativas necesarias para tener recursos y lineamientos. En esto se incluiría el mantener informados a los 
trabajadores de salud de los lineamientos implementados en el hospital, el equipo de respuesta tendrá los enlaces externos necesarios para obtener todo lo que se requiera. El enlace con el Instituto de Diagnóstico y Referencia Epidemiológica (InDRE) en México o su laboratorio de referencia en su país que realizará el diagnóstico o será el encargado de tener el enlace con el laboratorio internacional que lo realice. Se debe tener el equipo necesario para la toma y transporte de las muestras, llevando a cabo las medidas de bioseguridad; en este caso, se usará triple embalaje para la muestra que debe estar perfectamente identificada. El administrativo debe conocer que necesitará gestionar recursos extraordinarios, por ejemplo: mascarillas quirúrgicas y solución alcoholada en un momento dado, por lo que debe planificar las estrategias para ello, el equipo de respuesta planeará la implementación de áreas temporales para la colocación de pacientes, como evitar áreas sobrepobladas, principalmente en Urgencias, por lo que se requerirá aumentar el personal médico y de enfermería, lo que conlleva el apoyo de autoridades y administrativos.

El hospital debe implementar un sistema de vigilancia que permita la información oportuna, sistemática y verídica intrainstitucional y extrahospitalaria, por lo que se requiere el apoyo del Servicio de Sistemas, administrativo que provea del equipo y mecanismos adecuados y la experiencia del Servicio de Epidemiología.

5. Usar los controles de ingeniería y ambientales necesarios incluye la planeación de áreas en las que se atenderá a los casos sospechosos (sitios de aislamiento), esto puede ser difícil por la infraestructura del hospital, pero debe decidirse cómo implementar un área adecuada para colocar a los pacientes en cohorte o dar las indicaciones de separarlos en áreas de espera, así como direccionar el transporte del paciente ambulatorio o intrahospitalario para minimizar los riesgos a otros. Se debe mantener las áreas con una ventilación y filtros adecuados, al igual que la limpieza de ductos y rejillas. La limpieza y desinfección hospitalaria con la técnica de tres recipientes agua y jabón, agua para enjuague y solución clorada a 1,000 ppm para la desinfección es suficiente y efectiva; el manejo de ropa y la eliminación de desechos de acuerdo a nuestras normas establecidas que llevamos a cabo rutinariamente con los pacientes infectocontagiosos.

Hasta el 03 de marzo tenemos 90,870 casos de COVID-19 confirmados, de los cuales 10,566 se presentaron en 72 países fuera de China y los expertos comentan que los tres primeros donde se documentó la trasmisión clara de humano a humano fue en Alemania, Vietnam y Japón, lo que alerta a un posible aumento en el riesgo de transmisión del coronavirus por ahora en esos países. Los viajes internacionales son el riesgo inminente para todos, así como el pensar que a nosotros no nos pasará, la falta de información o la falta de conciencia al no tener precaución o no notificar para evitar problemas personales. Todo esto ocasiona que el riesgo exista para todas las personas y países. La OMS reportó un caso confirmado de un ciudadano chino que estuvo visitando nuestra hermosa Ciudad de México y el desconocimiento de todas las personas que tuvieron contacto con él, por lo que se iniciaron medidas siguiendo la ruta que él recuerda por supuestos. Así mismo, actualmente existen cinco casos confirmados en México.

\section{CONCLUSIÓN}

Hasta que suceden estas emergencias es cuando recordamos que el riesgo existe y ponemos atención en las medidas que deberíamos hacer cotidianamente y que olvidamos involuntariamente por la carga de trabajo o al darle prioridad a las actividades directas de atención del paciente, sin pensar que las medidas de prevención son parte fundamental de esta atención hacia el paciente. En primer plano la seguridad es para todos.

\section{REFERENCIAS}

1. Li Q, Guan X, Wu P, Wang X, Zhou L, Tong Y et al. Early transmission dynamics in Wuhan, China, of novel Coronavirus-infected pneumonia. N Engl J Med. 2020 Jan 29. doi: 10.1056/NEJMoa2001316.

2. Infection prevention and control during health care when novel coronavirus (COVID19) infection is suspected Interim guidance WHO/2019-COVID19/IPC/v2020.2

3. SSA, DGE Lineamiento estandarizado para la vigilancia epidemiológica y por laboratorio de enfermedad por 2019-COVID19.

4. UIES. Aviso epidemiológico CONAVE/04/2020/2019-COVID $27 / 02 / 2020$

5. UIES. Comunicado técnico diario nuevo coronavirus en el mundo (2019-COVID19) 25/02/2019.

6. Emergencia 2019-COVID19 Disponible en: https://www. who.int/es/news-room/detail/30-01-2020-statement-on-thesecond-meeting-of-the-international-health-regulations(2005)-emergency-committee-regarding-the-outbreak-of-novel-coronavirus-(2019-COVID19). 